\title{
REVIEW
}

\section{Gene therapy for malignant mesothelioma: beyond the infant years}

\author{
RG van der Most ${ }^{1,2}$, BWS Robinson ${ }^{1}$ and DJ Nelson ${ }^{1,3}$
}

\author{
${ }^{1}$ School of Medicine and Pharmacology, University of Western Australia, Nedlands, Western Australia, \\ Australia; ${ }^{2}$ Western Australian Institute of Medical Research, Nedlands, Western Australia, Australia \\ and ${ }^{3}$ School of Biomedical Sciences, Curtin University, Bentley, Western Australia, Australia
}

\begin{abstract}
Mesothelioma may be particularly well suited for gene therapy treatment owing to its accessibility, allowing both intrapleural and intratumoral gene delivery. At least four gene therapy trials have been carried out in mesothelioma patients, using different vector systems (adenovirus, vaccinia virus, irradiated tumor cells), and different transgenes (herpes simplex virus thymidine kinase (HSVtk) combined with ganciclovir, IL-2, IFN- $\beta$ ). Although small in scale, these trials have given an inkling of hope for therapeutic efficacy. However, it is clear that gene therapy protocols need to be optimized further. This paper will review progress made in (i) vector development, (ii) defining optimal transgenes, and (iii) gene delivery. Adenoviruses are the most commonly used vectors for gene therapy, and are continuously being improved. With respect to the nature of the transgenes, five categories can be distinguished: (i) 'suicide' or sensitivity genes (e.g., HSVtk), (ii) cytokines and other immune modulators, (iii) replacements for mutant tumor suppressor genes (e.g., p53), (iv) antiangiogenic proteins and (v) tumor antigens. It seems clear that expression of a single transgene is unlikely to be sufficient to eradicate a tumor, such as mesothelioma, that is diagnosed late in disease progression. Hence, multimodality therapy, including conventional therapy (chemo- and radiotherapy, surgery) with one or more transgenes has a higher chance of success.
\end{abstract}

Cancer Gene Therapy (2006) 13, 897-904. doi:10.1038/sj.cgt.7700935; published online 27 January 2006

Keywords: mesothelioma; gene therapy; adenovirus; immunotherapy

Despite considerable advances in our understanding of its pathogenesis and etiology, malignant mesothelioma remains only weakly responsive to standard modalities of cancer therapy. ${ }^{1}$ Thus, there is an urgent need for new therapeutic options, beyond chemotherapy and surgery, ${ }^{2}$ one such approach is gene therapy. ${ }^{3-5}$ The premise of gene therapy is that 'therapeutic' genes are administered into the tumor, upon which their expression in transfected tumor cells could alter the course of disease. For example, local expression of the transgenes could enhance sensitivity of tumor cells to therapy, change immune responses against the tumor, block angiogenesis or reverse the malignant phenotype of tumor cells.

\section{Mesothelioma gene therapy trials: the first lessons}

Gene therapy may be particularly relevant for malignant mesothelioma as it is localized to the pleural cavity and accessible for in vivo gene delivery. ${ }^{3,6}$ Indeed, several gene therapy clinical trials have now been conducted. In fact,

Correspondence: Dr RG van der Most, School of Medicine and Pharmacology, University of Western Australia, 4th Floor, G Block, Queen Elizabeth II Medical Center, Nedlands, Western Australia 6009, Australia.

E-mail: rvdmost@cyllene.uwa.edu.au

Received 22 July 2005; revised 9 October 2005; accepted 9 October

2005; published online 27 January 2006 the first human gene therapy trial approved in the US as primary cancer treatment was aimed at mesothelioma. This phase I clinical trial ${ }^{7,8}$ conducted by Albelda and co-workers from the University of Pennsylvania Medical Center, involved the use of a replication-deficient adenovirus recombinant expressing the thymidine kinase gene from herpes simplex virus (HSVtk). ${ }^{9}$ The HSVtk gene is the therapeutic gene: expression of this viral gene renders cells sensitive to the otherwise nontoxic antiviral drug ganciclovir. ${ }^{10}$ Thus, postgene therapy treatment of patients with ganciclovir selectively kills tumor cells expressing the HSVtk transgene. This approach was highly successful in preclinical studies ${ }^{11-14}$ and in a Phase I clinical trial, 21 mesothelioma patients were treated by intrapleural instillation of the HSVtk-expressing adenovirus recombinant. ${ }^{7,8}$ After 2 weeks, patients received intravenous ganciclovir. The investigators reported minimal side effect and found evidence for intratumoral transgene expression in 11 of 25 evaluable patients. However, no objective early antitumor responses were reported. The same group then conducted a second trial, involving six patients, with an optimized (second generation) adenovirus-HSVtk recombinant ${ }^{15}$ at higher doses and found that two of three surviving patients showed only minimal evidence of disease at six years post-treatment. ${ }^{1,16}$

A different approach to gene therapy, that is, immunogene therapy, was taken by our laboratory at the 
Sir Charles Gairdner Hospital (Western Australia, Australia). In an attempt to boost antitumor immune responses, tumor lesions were injected with a vaccinia virus recombinant expressing human interleukin-2 (IL-2). ${ }^{17}$ Not only has IL-2 a positive effect on antigenspecific T-cells responses, in that it extends T-cell survival, ${ }^{18}$ but this cytokine also has the capacity to block angiogenesis. ${ }^{19}$ Moreover, clinical trials with intrapleural IL-2 administration have been conducted for mesothelioma, and other tumors, and have yielded encouraging results. ${ }^{20-23}$ In our study, six mesothelioma patients were treated with the vaccinia virus recombinant. No systemic or local toxicities were observed, and, despite antibody responses, vaccinia virus-IL-2 mRNA gene expression persisted in tumor biopsies for up to 3 weeks. There was no evidence of excretion of virus or transmission to contacts. A T-cell infiltrate was detected in $50 \%$ of tumor biopsies at the site of injection. However, no clinical responses were observed, suggesting that the treatment regimen needs further optimization.

Finally, researchers from Louisiana State University Medical Center performed a Phase I clinical trial in which they tested a strategy to combine the beneficial effects of HSVtk gene therapy and immuno-gene therapy. ${ }^{24-26}$ Irradiated, allogeneic ovarian carcinoma cells were transduced with a retrovirus expressing HSVtk and administered intrapleurally. After $24 \mathrm{~h}$, patients were treated with ganciclovir. The rational behind this approach was that ganciclovir-mediated death of the ovarian carcinoma cells, could generate an immunological 'bystander effect' (i.e., enhanced antitumor $\mathrm{T}$-cell responses at the injection site of as well as at distant, nontransduced tumor sites). To enhance this immune response, BCG was used as an adjuvant. The transduced ovarian carcinoma cells migrated to mesothelioma lesions within $24 \mathrm{~h}$ after intrapleural administration. ${ }^{26}$ The investigators observed minimal side effects and significant post treatment increases in the percentage of CD8 $\mathrm{T}$ lymphocytes in pleural fluid. No information on clinical responses has been reported so far.

\section{Improving gene therapy}

These three seminal clinical studies in the field of mesothelioma gene therapy illustrate the key issues that will determine the success of future clinical trials. First, the choice of the vector carrying the transgene is important. The three vectors used in the mesothelioma trials, that is, replication-deficient adenovirus, vaccinia virus and irradiated tumor cells, all have their advantages and disadvantages, as we will discuss in more detail below. The associated issue is the efficiency and route of vector delivery. How can we target as many tumor cells as possible and achieve durable transgene expression? And, given that it is probably impossible to reach all tumor cells, how can we maximize antitumor bystander effects? Finally, there are clearly different strategies in the choice of the transgene(s). Again, the mesothelioma clinical trials demonstrate the point. One strategy is to use genes that will enhance the efficacy of subsequent chemo- or immunotherapy, as exemplified by HSVtk gene therapy. The other approach is to stimulate the patients' own immune system to attack the tumor, by using, for instance, cytokine genes such as IL-2. An exciting possibility is that the two approaches could be synergistic when used in combination.

In the following sections, we will discuss recent progress made in these areas. Although the initial enthusiasm for gene therapy has been tempered, as anticancer benefits have not yet been fully realized, the current focus on vector and delivery technology will undoubtedly lead to clinically viable protocols.

\section{Gene therapy vectors}

Recombinant adenoviruses are the most widely used gene therapy vectors. ${ }^{4,27}$ Adenoviruses are DNA viruses with a $36 \mathrm{~kb}$ genome. Up to $8 \mathrm{~kb}$ of foreign DNA can be inserted in the four early transcription units E1-E4. In the first generation of vectors, foreign DNA was inserted in place of the E1 or E3 regions. These first generation vectors induced strong inflammatory responses, which has both advantages and disadvantages. The obvious problem is that the inflammatory response impairs transgene expression, obstructs successful readministration and could even result in life-threatening toxicity. To address this problem, second generation vectors were constructed with further deletions in the E2b and E4 regions, thereby limiting antiviral immune responses. However, for cancer gene therapy, the induction of intratumoral inflammatory responses is probably beneficial. A different strategy to control the toxicity of acute inflammatory responses is to combine adenovirus-mediated gene therapy with immunosuppressive drugs such as corticosteroids, cyclosporin and FK506. In fact, the combination of HSVtk expressing adenoviruses with systemic corticosteroid treatment has been trialed in mesothelioma patients. ${ }^{28}$ The results suggested that combination treatment could limit acute toxicity but did not inhibit antiadenoviral B- and T-cell responses. For the treatment of mesothelioma, this could be a favorable outcome.

First generation E1-deleted recombinants vectors are replication incompetent because the E1 gene product is essential for viral replication. This is an important safety feature, but it also limits expression of the transgene to the initially infected cells. In contrast, E3-deleted recombinants are replication competent. ${ }^{4,29}$ These viruses can infect neighboring cells, and spread the transgenes. A potential limitation is the cellular receptor of the recombinant virus: most adenovirus vectors are based on the group $\mathrm{C}$ adenovirus serotype 5 strain (Ad5), ${ }^{30}$ which uses the coxsackie and adenovirus receptor (CAR) as its receptor. This receptor is poorly expressed on dendritic cells (DC) and primary tumor cells, thus limiting spread of the recombinant virus. This issue has been solved by replacing the receptor-binding Ad5 fiber proteins with the fiber proteins from group B serotype viruses, which use the more widely expressed CD46 protein as the cellular 
receptor. ${ }^{31}$ On the other hand, replication competent viral recombinants carry the risk of disseminated viremia. To solve this problem, conditionally replication competent adenoviruses have been constructed by mutating the E1a or E1b genes. ${ }^{32}$ E1b normally inactivates p53 and, as originally reported, E1b-deficient adenovirus, ONYX-015, replicates only in p53-negative tumor cells. ${ }^{33,34}$ It is now clear, however, that replication of ONYX-015 is not entirely dependent on the p53-status of tumor cells. ${ }^{35,36}$ Indeed, certain p53-positive mesothelioma cell lines were killed by ONYX-015. ${ }^{37}$

Recombinant vaccinia viruses have the capacity to direct high-level transgene expression in a wide variety of cell types. As the generation of vaccinia virus recombinants involves replacement of the viral thymidine kinase gene by the transgene, recombinant vaccinia viruses, such as the one used in our clinical trial, are replication restricted. Vaccinia virus causes a lytic infection and, similar to the first generation adenovirus recombinants, induces strong antiviral immune responses. ${ }^{26,38}$ The advantage of this is that tumor antigens of vaccinia virus infected, dying tumor cells are presented to the immune systems in a proinflammatory context. In the context of immuno-gene therapy, the result could be a strong antitumor immune response.

The use of irradiated autologous or allogeneic tumor cells as gene therapy vectors has yielded promising results in preclinical models. Tumor cells have been engineered to express HSVtk, ${ }^{24}$ but also genes encoding cytokines or costimulatory molecules. An important advantage of this approach is that transfected tumor cells can present tumor antigens in an immunogenic fashion, thereby enhancing antitumor T-cell responses. ${ }^{39}$ A similar argument can be made for the use of DC as transgene carriers. DC are the most effective antigen presenting cells and are found in all tissues and organs of the body. ${ }^{40-42}$ They sample antigens in peripheral tissues and present these to $\mathrm{T}$ cells in secondary lymphoid organs. Thus, intrapleural or intratumoral instillation of activated DC, expressing proinflammatory cytokines, could generate or enhance antitumor immune responses. Recent studies have demonstrated the feasibility of transfecting human DC with genes encoding cytokines, ${ }^{43}$ with objective responses observed in some patients. ${ }^{44}$

Alternative gene therapy vectors include retroviruses, lentiviruses, herpesviruses, and adeno-associated virus. None of these vectors has been used for mesothelioma so far. A detailed discussion on the pros and cons of these vector systems for cancer gene therapy is provided by several recent reviews. 5,27

\section{The payload: which genes to express?}

Five categories of transgenes can be distinguished. First, there are sensitivity or 'suicide' genes that render the tumor cells selectively susceptible to therapy. ${ }^{45}$ The HSVtk gene is the best example, but there are other candidates. Bacterial cytosine deaminase gene converts the pro-drug 5-fluorocytosine into a cytotoxic one. ${ }^{46}$
Adenovirus-mediated expression of the cytosine deaminase gene, in combination with 5-fluorocytosine therapy, displayed significant antitumor effects in vitro and in preclinical models $^{47,48}$ and has been tested in a Phase I clinical trial. ${ }^{49}$ Furthermore, increased radiosensitivity was conferred by iNOS (inducible nitric oxide synthetase), ${ }^{50}$ cytosine deaminase (in combination with 5-fluorocytosine therapy) ${ }^{51}$ and p53 gene transfer. ${ }^{52}$ Use of the radiation-inducible WAF1 promoter to drive expression of, for instance, iNOS, could enhance this even further. ${ }^{53}$ Of these options, only HSVtk has been studied in mesothelioma so far. A major advantage of HSVtk is a 'bystander effect', which requires only a small percentage (10-20\%) of tumor cells to be transduced with HSVtk, thereby overcoming gene delivery limitations. ${ }^{54-56}$ The nature of this bystander effect is complex and appears to involve passage of toxic ganciclovir metabolites from transduced to nontransduced cells via gap junctions or apoptotic vesicles, ${ }^{57}$ and the induction of antitumor immune responses capable of killing tumor cells not expressing the HSVtk transgene. ${ }^{58,59}$

The second category of transgenes entails immune stimulatory genes, including cytokines, ${ }^{60}$ chemokines, and costimulatory molecules ('immuno-gene therapy'). Many different molecules, for example, IL-2, ${ }^{61}$ IL- $4,{ }^{62}$ IL-12, ${ }^{63}$ IL-15, ${ }^{64}$ IL-21, ${ }^{65}$ B7.1/B7.2, ${ }^{66}$ GM-CSF, ${ }^{67}$ IFN- $\alpha$, IFN- $\beta,{ }^{68}$ IFN- $\gamma,{ }^{69}$ TNF- $\alpha,{ }^{70}$ have been studied and shown to stimulate antitumor immunity in the context of gene therapy. The effects of these genes have been mostly studied in the context of transduced tumor cell lines and adenovirus recombinants. Of particular interest for mesothelioma is an adenovirus recombinant expressing IFN- $\beta{ }^{68}$ In preclinical studies, this recombinant showed enhanced efficacy in combination with debulking surgery, chemotherapy (gemcitabin and cisplatin), or cyclooxygenase-2 inhibition. ${ }^{1,71,72}$ A similar synergy was seen when GM-CSF or B7.1 gene therapy was combined with debulking surgery ${ }^{67}$ or when IFN- $\alpha$ treatment was combined with chemotherapy. ${ }^{73}$ The fact that IFN- $\alpha$ and $-\beta$ stimulate crosspriming of $\mathrm{CD} 8+\mathrm{T}$ cells, ${ }^{74}$ suggests that this immune priming step may be rate-limiting in the efficacy of conventional treatments. ${ }^{75}$ The IFN- $\beta$ adenovirus recombinant was subsequently studied in a Phase I clinical trial at the University of Pennsylvania Medical Center, in collaboration with the Biogen-IDEC Corporation (Cambridge, MA). ${ }^{1}$ Eight patients (six mesothelioma patients, one ovarian cancer and one metastatic lung cancer patient) were treated with a single, intrapleural dose $\left(9 \times 10^{11}-3 \times 10^{12}\right.$ viral particles $)$ of the IFN- $\beta$ producing adenovirus recombinant. At day 60, four patients of the seven who underwent repeat imaging studies had progressive disease, and three patients had stable disease or partial responses.

The third category of therapeutic genes is based on a 'gene replacement' principle. Mutated or absent tumor suppressor genes (in particular the p53 tumor suppressor gene), which are responsible for the malignant phenotype, are replaced by their normal counterparts. For example, restoration of wt-p53 function in p53-deficient tumor cells induces malignant cell death via apoptosis or growth 
arrest, despite the presence of multiple genetic abnormalities within the cell. ${ }^{76}$ Although mutations in the p53 gene are uncommon in malignant mesothelioma, ${ }^{77}$ overexpression of wt-p53 may still be an option because inhibitor proteins such as MDM2 and SV40 large $\mathrm{T}$ antigen may impede p53 function. ${ }^{69}$ This is supported by studies showing that transfection of human meso thelioma cells with an adenovirus recombinant expressing wt-p53 induced apoptosis and inhibited tumor cell growth in vitro. ${ }^{78}$ In contrast to $\mathrm{p} 53$, inactivation of the INK $4 \mathrm{a} /$ ARF locus appears to be common in mesothelioma cells. ${ }^{79-81}$ The INK4a/ARF gene generates two products, the p16INK4a protein, a cyclin-dependent kinase inhibitor, and p14ARF, which blocks MDM2-mediated inhibition of $\mathrm{p} 53 .{ }^{82}$ Thus, deletion of the INK4a/ARF gene can lead to uncontrolled proliferation despite the presence of wild-type p53. In fact, the absence of the p14ARF protein in mesothelioma cells may explain why the ONYX-015 vector kills these cells. ${ }^{37}$ Moreover, adenovirus-mediated replacement p16INK4a, and to a lesser extent p14ARF, promotes tumor cell death and tumor suppression. ${ }^{83-85}$ Intratumoral injection of an adenovirus recombinant expressing p16INK4a inhibited growth of established human mesothelioma xenografts in immunodeficient mice and prolonged survival. ${ }^{78}$ An alternative method to inhibit malignant cells is the introduction proapoptotic genes. Adenovirus-mediated transfer of the proapoptotic Bcl-2 family member Bak induced apoptosis in mesothelioma cell lines. ${ }^{86,87}$ A general disadvantage of these gene replacement strategies is the lack of bystander effects.

The fourth group of potential transgenes comprises antiangiogenic genes. ${ }^{88,89}$ Proteins such as angiostatin and endostatin, or vascular endothelial growth factor (VEGF) antagonists, such as truncated versions of the VEGFreceptors flk1 and flt1, have shown antitumor effects in the context of adenovirus-mediated gene transfer. ${ }^{90}$ Simultaneous expression of soluble flt 1 and human pigment endothelial-derived factor (PEDF) via recombinant adenoviruses inhibited mesothelioma tumor growth in a preclinical model. ${ }^{91}$ Importantly, cytokines such as IL-2 and IL-12 also show potent antiangiogenic effects, ${ }^{92}$ as demonstrated in our laboratory in a preclinical mesothelioma model. ${ }^{19}$

Finally, the fifth category of potential transgenes comprises tumor antigens, that is, cellular proteins that have altered expression in tumor cells as compared to normal cells. Expressing tumor antigens in a proinflammatory fashion should boost antitumor immune responses. This strategy, which is also referred to as 'therapeutic cancer vaccination', has met some success in melanoma patients. ${ }^{93}$ However, a prerequisite is that tumor antigens are known, and this is not the case for mesothelioma although both mesothelin and the SV40 large $\mathrm{T}$ antigen may be possible candidates. Mesothelin is overexpressed in most mesotheliomas, ${ }^{94}$ and has the capacity to induce CD8 T-cell responses, as shown by Jaffee and co-workers. ${ }^{95}$ The role of SV40 in mesothelioma is more controversial ${ }^{96,97}$ but vaccinia virus recombinants expressing the large $\mathrm{T}$ antigen are being developed as potential antimesothelioma agents. ${ }^{98}$ Thus, at present, therapeutic vaccination for the treatment of malignant mesothelioma is still in its infancy.

\section{Gene delivery}

The limiting factor in the efficacy of gene therapy as anticancer treatment is the efficiency of gene delivery. Most mesotheliomas are localized in the pleural cavity, and are therefore more accessible than other (metastatic) cancers. However, it is still unlikely that treatment will reach all malignant cells. Thus, the success of gene therapy depends on systemic 'bystander' effects. The best candidate to accomplish this in anticancer treatments is the immune system.

Most clinical and preclinical studies have used intrapleural administration of gene therapy vectors. In the case of the HSVtk-expressing adenovirus recombinant, this resulted in high-level, albeit superficial, expression of the transgene in tumor cells. ${ }^{1}$ The alternative is direct intratumoral injection. This is an approach that was pioneered in our laboratory using serial injections of IFN- $\alpha$, IL-2, continuous intratumoral infusion, of GM-CSF ${ }^{60,99}$ and, with respect to gene therapy, the IL-2 expressing vaccinia virus recombinant. ${ }^{17}$ It has also been demonstrated that endoscopic ultrasound can accurately deliver gene therapy vectors, that is, ONYX-015 in unresectable pancreatic carcinoma. ${ }^{100}$ These studies illustrate the feasibility of directly targeting the tumor.

\section{Future directions}

Given the accessibility of mesotheliomas for gene therapy vectors, it seems likely that most room of improvement lies in the vector technology itself. ${ }^{3}$ The relatively inefficient delivery of transgenes in tumor tissue provides a compelling argument to further develop viral gene therapy vectors, since replication competent viruses have the capacity to spread through the tumor and amplify the transgene, in contrast to gene transfer via tumor cells or DC. Also, gene transfer via infection, mediated by viral particles, is more efficient than naked DNA transfection. Thus, as there is no shortage of potential transgenes, future research in the field of gene therapy will most likely be directed at improvement of vector technology. In the case of viral vectors, it will be important to define the balance between viral replication and antiviral immunity. Given the history of anticancer gene therapy, it seems likely that the further development of adenovirus vectors will receive most attention in the near future. In particular, expression of transgenes under the control of tumor-specific promoters is promising, as shown for the human telomerase promoter. ${ }^{101}$ Since mesothelin is highly upregulated in mesothelioma, ${ }^{94,102}$ use of the mesothelin promoter ${ }^{103}$ to drive adenovirus-based transgene expression could show potential. Beyond adenovirus vectors, it is notable that the potential of vaccinia virus recombinants as (immuno-) gene therapy vectors has remained 
relatively underdeveloped. Vaccinia viruses can trigger massive immune responses. ${ }^{104}$ The challenge will be to redirect this response towards the tumor.

An interesting approach to target tumor cells by recombinant vaccinia viruses and attenuated bacteria has recently been described. ${ }^{105}$ Intravenous injection of recombinant vaccinia viruses or attenuated Salmonella or Shigella bacteria resulted in preferential replication of these organisms in tumor tissue, presumably because the tumor provides an 'immuno privileged' site. Although this technique is clearly in its infancy, it could provide new opportunities to reach more tumor cells as well as small metastatic deposits. Whereas vaccinia virus recombinants have already been used in gene therapy trials, ${ }^{17}$ the use of attenuated bacteria as gene therapy vehicles is relatively novel. Nevertheless, encouraging results have been reported with attenuated Salmonella bacteria, harboring plasmids that encode tumor antigens, cytokines and antiangiogenic proteins, as therapeutic vaccines in preclinical models. ${ }^{106,107}$

A radically different approach to cancer gene therapy involves the use of replicating, oncolytic viruses. This strategy is based on the observation that most tumor cells have impaired antiviral responses that makes them more sensitive for cytolytic viruses. Examples of such oncolytic viruses include reovirus, ${ }^{108}$ measles and mumps virus 109 and sindbis virus. ${ }^{110}$ The efficacy of the ONYX-015 adenovirus also depends on its oncolytic properties. One such strategy that has been evaluated in mesothelioma is based on a non-neurovirulent HSV variant. ${ }^{111}$ A mutant virus was created that lacked both copies of the ICP-34.5 gene. This resulted in a replication-restricted virus, which preferentially replicated in tumor cells. Human malignant mesothelioma cells supported growth of the mutant virus and were lysed as a result.

\section{Concluding remarks}

Gene therapy has not yet delivered the anticancer response hoped for. Instead, this area has become increasingly complex as it is now realized that the vector, the route and the desired transgene/s need to be identified and optimized for each disease. Nonetheless, mesothelioma is one cancer type that may be particularly well suited for gene therapy due to its accessibility and promising results to date. It is also clear that expression of a single transgene is unlikely to be sufficient to eradicate a tumor (such as mesothelioma) that is diagnosed late in disease progression. Hence, attacking several facets of tumor immuno-biology has a higher chance of success. This combination could consist of genes coding for molecules that induce apoptosis with ones that inhibit angiogenesis and/or function as immune adjuvants.

\section{References}

1 Sterman DH, Albelda SM. Advances in the diagnosis, evaluation, and management of malignant pleural mesothelioma. Respirology 2005; 10: 266-283.
2 Nowak AK, Lake RA, Kindler HL, Robinson BW. New approaches for mesothelioma: biologics, vaccines, gene therapy, and other novel agents. Semin Oncol 2002; 29: 82-96.

3 Albelda SM, Wiewrodt R, Sterman DH. Gene therapy for lung neoplasms. Clin Chest Med 2002; 23: 265-277.

$4 \mathrm{Wu}$ Q, Moyana T, Xiang J. Cancer gene therapy by adenovirus-mediated gene transfer. Curr Gene Ther 2001; 1: 101-122.

5 Gottesman MM. Cancer gene therapy: an awkward adolescence. Cancer Gene Ther 2003; 10: 501-508.

6 Nelson D, Robinson B, Allan J, van der Most R. Gene therapy of mesothelioma. Expert Opin Biol Ther 2005; 5: $1039-1049$.

7 Sterman DH, Kaiser LR, Albelda SM. Gene therapy for malignant pleural mesothelioma. Hematol Oncol Clin North Am 1998; 12: 553-568.

8 Molnar-Kimber KL, Sterman DH, Chang M, Kang EH, ElBash M, Lanuti $\mathrm{M}$ et al. Impact of preexisting and induced humoral and cellular immune responses in an adenovirusbased gene therapy phase I clinical trial for localized mesothelioma. Hum Gene Ther 1998; 9: 2121-2133.

9 Smythe WR, Hwang HC, Amin KM, Eck SL, Davidson BL, Wilson JM et al. Use of recombinant adenovirus to transfer the herpes simplex virus thymidine kinase (HSVtk) gene to thoracic neoplasms: an effective in vitro drug sensitization system. Cancer Res 1994; 54: 2055-2059.

10 Moolten FL. Tumor chemosensitivity conferred by inserted herpes thymidine kinase genes: paradigm for a prospective cancer control strategy. Cancer Res 1986; 46: 5276-5281.

11 Moolten FL, Wells JM. Curability of tumors bearing herpes thymidine kinase genes transferred by retroviral vectors. J Natl Cancer Inst 1990; 82: 297-300.

12 Elshami AA, Kucharczuk JC, Zhang HB, Smythe WR, Hwang HC, Litzky LA et al. Treatment of pleural mesothelioma in an immunocompetent rat model utilizing adenoviral transfer of the herpes simplex virus thymidine kinase gene. Hum Gene Ther 1996; 7: 141-148.

13 Kucharczuk JC, Raper S, Elshami AA, Amin KM, Sterman DH, Wheeldon EB et al. Safety of intrapleurally administered recombinant adenovirus carrying herpes simplex thymidine kinase DNA followed by ganciclovir therapy in nonhuman primates. Hum Gene Ther 1996; 7: 2225-2233.

14 Esandi MC, van Someren GD, Vincent AJ, van Bekkum DW, Valerio D, Bout A et al. Gene therapy of experimental malignant mesothelioma using adenovirus vectors encoding the HSVtk gene. Gene Therapy 1997; 4: 280-287.

15 Lanuti M, Gao GP, Force SD, Chang MY, El Kouri C, Amin KM et al. Evaluation of an E1E4-deleted adenovirus expressing the herpes simplex thymidine kinase suicide gene in cancer gene therapy. Hum Gene Ther 1999; 10: 463-475.

16 Sterman DH, Recio A, Vachani A, Sun J, Cheung L, DeLong $\mathrm{P}$ et al. Long-term follow-up of patients with malignant pleural mesothelioma receiving high-dose adenovirus herpes simplex thymidine kinase/ganciclovir suicide gene therapy. Clin Cancer Res 2005; 11: 7444-7453.

17 Mukherjee S, Haenel T, Himbeck R, Scott B, Ramshaw I, Lake RA et al. Replication-restricted vaccinia as a cytokine gene therapy vector in cancer: persistent transgene expression despite antibody generation. Cancer Gene Ther 2000; 7: 663-670.

18 Blattman JN, Grayson JM, Wherry EJ, Kaech SM, Smith KA, Ahmed R. Therapeutic use of IL-2 to enhance antiviral T-cell responses in vivo. Nat Med 2003; 9: 540-547. 
19 Jackaman C, Bundell CS, Kinnear BF, Smith AM, Filion P, van Hagen D et al. IL-2 intratumoral immunotherapy enhances CD8 $+\mathrm{T}$ cells that mediate destruction of tumor cells and tumor-associated vasculature: a novel mechanism for IL-2. J Immunol 2003; 171: 5051-5063.

20 Castagneto B, Zai S, Mutti L, Lazzaro A, Ridolfi R, Piccolini $\mathrm{E}$ et al. Palliative and therapeutic activity of IL-2 immunotherapy in unresectable malignant pleural mesothelioma with pleural effusion: results of a phase II study on 31 consecutive patients. Lung Cancer 2001; 31 303-310.

21 Goey SH, Eggermont AM, Punt CJ, Slingerland R, Gratama JW, Oosterom R et al. Intrapleural administration of interleukin 2 in pleural mesothelioma: a phase I-II study. Br J Cancer 1995; 72: 1283-1288.

22 Astoul P, Picat-Joossen D, Viallat JR, Boutin C. Intrapleural administration of interleukin-2 for the treatment of patients with malignant pleural mesothelioma: a Phase II study. Cancer 1998; 83: 2099-2104.

23 Trudel S, Trachtenberg J, Toi A, Sweet J, Li ZH, Jewett M et al. A phase I trial of adenovector-mediated delivery of interleukin-2 (AdIL-2) in high-risk localized prostate cancer. Cancer Gene Ther 2003; 10: 755-763.

24 Schwarzenberger P, Lei D, Freeman SM, Ye P, Weinacker A, Theodossiou $\mathrm{C}$ et al. Antitumor activity with the HSVtk-gene-modified cell line PA-1-STK in malignant mesothelioma. Am J Respir Cell Mol Biol 1998; 19: 333-337.

25 Schwarzenberger P, Harrison L, Weinacker A, Marrogi A, Byrne P, Ramesh $\mathrm{R}$ et al. The treatment of malignant mesothelioma with a gene modified cancer cell line: a phase I study. Hum Gene Ther 1998; 9: 2641-2649.

26 Harrison Jr LH, Schwarzenberger PO, Byrne PS, Marrogi AJ, Kolls JK, McCarthy KE. Gene-modified PA1-STK cells home to tumor sites in patients with malignant pleural mesothelioma. Ann Thorac Surg 2000; 70: 407-411.

27 Vorburger SA, Hunt KK. Adenoviral gene therapy. Oncologist 2002; 7: 46-59.

28 Sterman DH, Molnar-Kimber K, Iyengar T, Chang M, Lanuti M, Amin KM et al. A pilot study of systemic corticosteroid administration in conjunction with intrapleural adenoviral vector administration in patients with malignant pleural mesothelioma. Cancer Gene Ther 2000; 7: $1511-1518$

29 Lichtenstein DL, Toth K, Doronin K, Tollefson AE, Wold WS. Functions and mechanisms of action of the adenovirus E3 proteins. Int Rev Immunol 2004; 23: 75-111.

30 Shayakhmetov DM, Li ZY, Gaggar A, Gharwan H, Ternovoi V, Sandig V et al. Genome size and structure determine efficiency of postinternalization steps and gene transfer of capsid-modified adenovirus vectors in a cell-type-specific manner. J Virol 2004; 78: 10009-10022.

31 Gaggar A, Shayakhmetov DM, Lieber A. CD46 is a cellular receptor for group B adenoviruses. Nat Med 2003; 9: $1408-1412$.

32 Dobbelstein M. Replicating adenoviruses in cancer therapy. Curr Top Microbiol Immunol 2004; 273: 291-334.

33 Heise C, Sampson-Johannes A, Williams A, McCormick F, Von Hoff DD, Kirn DH. ONYX-015, an E1B geneattenuated adenovirus, causes tumor-specific cytolysis and antitumoral efficacy that can be augmented by standard chemotherapeutic agents. Nat Med 1997; 3: 639-645.

34 Bischoff JR, Kirn DH, Williams A, Heise C, Horn S, Muna $\mathrm{M}$ et al. An adenovirus mutant that replicates selectively in p53-deficient human tumor cells. Science 1996 274: $373-376$.
35 Rothmann T, Hengstermann A, Whitaker NJ, Scheffner M, zur Hausen H. Replication of ONYX-015, a potential anticancer adenovirus, is independent of p53 status in tumor cells. J Virol 1998; 72: 9470-9478.

36 Harada JN, Berk AJ. p53-Independent and -dependent requirements for $\mathrm{E} 1 \mathrm{~B}-55 \mathrm{~K}$ in adenovirus type 5 replication. J Virol 1999; 73: 5333-5344.

37 Yang CT, You L, Uematsu K, Yeh CC, McCormick F, Jablons DM. p14(ARF) modulates the cytolytic effect of ONYX-015 in mesothelioma cells with wild-type p53. Cancer Res 2001; 61: 5959-5963.

38 Miller JD, van der Most RG, Glidewell JT, Murali-Krishna $\mathrm{K}$, Mahar P, Edupuganti S et al. Primary antiviral CD8 T cell responses to live yellow fever and smallpox immunization in humans. Manuscript in preparation.

39 Rodriguez-Lecompte JC, Kruth S, Gyorffy S, Wan YH, Gauldie J. Cell-based cancer gene therapy: breaking tolerance or inducing autoimmunity? Anim Health Res Rev 2004; 5: 227-234

40 Caux C, Liu YJ, Banchereau J. Recent advances in the study of dendritic cells and follicular dendritic cells. Immunol Today 1995; 16: 2-4.

41 Steinman RM. The dendritic cell system and its role in immunogenicity. Annu Rev Immunol 1991; 9: 271-296.

42 Heath WR, Belz GT, Behrens GM, Smith CM, Forehan SP, Parish IA et al. Cross-presentation, dendritic cell subsets, and the generation of immunity to cellular antigens. Immunol Rev 2004; 199: 9-26.

43 Arthur JF, Butterfield LH, Roth MD, Bui LA, Kiertscher $\mathrm{SM}$, Lau R et al. A comparison of gene transfer methods in human dendritic cells. Cancer Gene Ther 1997; 4: 17-25.

44 Ridgway D. The first 1000 dendritic cell vaccinees. Cancer Invest 2003; 21: 873-886.

45 Freeman SM, Whartenby KA, Freeman JL, Abboud CN, Marrogi AJ. In situ use of suicide genes for cancer therapy. Semin Oncol 1996; 23: 31-45.

46 Hirschowitz EA, Ohwada A, Pascal WR, Russi TJ, Crystal RG. In vivo adenovirus-mediated gene transfer of the Escherichia coli cytosine deaminase gene to human colon carcinoma-derived tumors induces chemosensitivity to 5-fluorocytosine. Hum Gene Ther 1995; 6: 1055-1063.

47 Ohwada A, Hirschowitz EA, Crystal RG. Regional delivery of an adenovirus vector containing the Escherichia coli cytosine deaminase gene to provide local activation of 5-fluorocytosine to suppress the growth of colon carcinoma metastatic to liver. Hum Gene Ther 1996; 7: $1567-1576$.

48 Dong Y, Wen P, Manome Y, Parr M, Hirshowitz A, Chen $\mathrm{L}$ et al. In vivo replication-deficient adenovirus vectormediated transduction of the cytosine deaminase gene sensitizes glioma cells to 5-fluorocytosine. Hum Gene Ther 1996; 7: 713-720.

49 Crystal RG, Hirschowitz E, Lieberman M, Daly J, Kazam $\mathrm{E}$, Henschke $\mathrm{C}$ et al. Phase I study of direct administration of a replication deficient adenovirus vector containing the E. coli cytosine deaminase gene to metastatic colon carcinoma of the liver in association with the oral administration of the pro-drug 5-fluorocytosine. Hum Gene Ther 1997; 8: 985-1001.

50 Wang Z, Cook T, Alber S, Liu K, Kovesdi I, Watkins SK et al. Adenoviral gene transfer of the human inducible nitric oxide synthase gene enhances the radiation response of human colorectal cancer associated with alterations in tumor vascularity. Cancer Res 2004; 64: 1386-1395.

51 Anello R, Cohen S, Atkinson G, Hall SJ. Adenovirus mediated cytosine deaminase gene transduction and 
5-fluorocytosine therapy sensitizes mouse prostate cancer cells to irradiation. J Urol 2000; 164: 2173-2177.

52 Kawabe S, Munshi A, Zumstein LA, Wilson DR, Roth JA, Meyn RE. Adenovirus-mediated wild-type p53 gene expression radiosensitizes non-small cell lung cancer cells but not normal lung fibroblasts. Int J Radiat Biol 2001; 77: 185-194.

53 Worthington J, McCarthy HO, Barrett E, Adams C, Robson T, Hirst DG. Use of the radiation-inducible WAF1 promoter to drive iNOS gene therapy as a novel anti-cancer treatment. J Gene Med 2004; 6: 673-680.

54 Freeman SM, Whartenby KA, Freeman JL, Abboud CN, Marrogi AJ. In situ use of suicide genes for cancer therapy. Semin Oncol 1996; 23: 31-45.

55 Freeman SM, Abboud CN, Whartenby KA, Packman $\mathrm{CH}$, Koeplin DS, Moolten FL et al. The 'bystander effect': tumor regression when a fraction of the tumor mass is genetically modified. Cancer Res 1993; 53: 5274-5283.

56 Hirschowitz EA, Ohwada A, Pascal WR, Russi TJ, Crystal RG. In vivo adenovirus-mediated gene transfer of the Escherichia coli cytosine deaminase gene to human colon carcinoma-derived tumors induces chemosensitivity to 5-fluorocytosine. Hum Gene Ther 1995; 6: 1055-1063.

57 Elshami AA, Kucharczuk JC, Zhang HB, Smythe WR, Hwang HC, Litzky LA et al. Treatment of pleural mesothelioma in an immunocompetent rat model utilizing adenoviral transfer of the herpes simplex virus thymidine kinase gene. Hum Gene Ther 1996; 7: 141-148.

58 Pope IM, Poston GJ, Kinsella AR. The role of the bystander effect in suicide gene therapy. Eur $J$ Cancer 1997; 33: 1005-1016.

59 Hamel W, Magnelli L, Chiarugi VP, Israel MA. Herpes simplex virus thymidine kinase/ganciclovir-mediated apoptotic death of bystander cells. Cancer Res 1996; 56: $2697-2702$

60 Robinson BW, Mukherjee SA, Davidson A, Morey S, Musk AW, Ramshaw I et al. Cytokine gene therapy or infusion as treatment for solid human cancer. J Immunother 1998; 21: 211-217.

61 Fearon ER, Pardoll DM, Itaya T, Golumbek P, Levitsky HI, Simons JW et al. Interleukin-2 production by tumor cells bypasses $\mathrm{T}$ helper function in the generation of an antitumor response. Cell 1990; 60: 397-403.

62 Golumbek PT, Lazenby AJ, Levitsky HI, Jaffee LM, Karasuyama $\mathrm{H}$, Baker $\mathrm{M}$ et al. Treatment of established renal cancer by tumor cells engineered to secrete interleukin-4. Science 1991; 254: 713-716.

63 Caminschi I, Venetsanakos E, Leong CC, Garlepp MJ, Robinson BW, Scott B. Interleukin-12 induces an effective antitumor response in maligant mesothelioma. Am J Respir Cell Mol Biol 1998; 21: 738-746.

64 Croce M, Meazza R, Orengo AM, Radic L, De Giovanni B, Gambini $\mathrm{C}$ et al. Sequential immunogene therapy with interleukin-12- and interleukin-15-engineered neuroblastoma cells cures metastatic disease in syngeneic mice. Clin Cancer Res 2005; 11: 735-742.

65 Kishida T, Asada H, Itokawa Y, Cui FD, Shin-Ya M, Gojo $\mathrm{S}$ et al. Interleukin (IL)-21 and IL-15 genetic transfer synergistically augments therapeutic antitumor immunity and promotes regression of metastatic lymphoma. Mol Ther 2003; 8: 552-558.

66 Leong CC, Marley JV, Loh S, Milech N, Robinson BW, Garlepp MJ. Transfection of the gene for B7-1 but not B7-2 can induce immunity to murine malignant mesothelioma. Int J Cancer 1997; 71: 476-482.
67 Mukherjee S, Nelson D, Loh S, van Bruggen I, Palmer LJ, Leong $\mathrm{C}$ et al. The immune anti-tumor effects of GM-CSF and B7-1 gene transfection are enhanced by surgical debulking of tumor. Cancer Gene Ther 2001; 8: $580-588$.

68 Odaka M, Sterman DH, Wiewrodt R, Zhang Y, Kiefer M, Amin KM et al. Eradication of intraperitoneal and distant tumor by adenovirus-mediated interferon-beta gene therapy is attributable to induction of systemic immunity. Cancer Res 2001; 61: 6201-6212.

69 Gattacceca F, Pilatte Y, Billard C, Monnet I, Moritz S, Le Carrou $\mathrm{J}$ et al. Ad-IFN gamma induces antiproliferative and antitumoral responses in malignant mesothelioma. Clin Cancer Res 2002; 8: 3298-3304.

70 Asher AL, Mule JJ, Kasid A, Restifo NP, Salo JC, Reichert $\mathrm{CM}$ et al. Murine tumor cells transduced with the gene for tumor necrosis factor-alpha. Evidence for paracrine immune effects of tumor necrosis factor against tumors. J Immunol 1991; 146: 3227-3234.

71 Kruklitis RJ, Singhal S, Delong P, Kapoor V, Sterman DH, Kaiser LR et al. Immuno-gene therapy with interferon-beta before surgical debulking delays recurrence and improves survival in a murine model of malignant mesothelioma. J Thorac Cardiovasc Surg 2004; 127: 123-130.

72 DeLong P, Tanaka T, Kruklitis R, Henry AC, Kapoor V, Kaiser LR et al. Use of cyclooxygenase-2 inhibition to enhance the efficacy of immunotherapy. Cancer Res 2003; 63: $7845-7852$.

73 Upham JW, Musk AW, van Hazel G, Byrne M, Robinson BW. Interferon alpha and doxorubicin in malignant mesothelioma: a phase II study. Aust NZ J Med 1993; 23: 683-687.

74 Le Bon A, Etchart N, Rossmann C, Ashton M, Hou S, Gewert D et al. Cross-priming of CD8 $+\mathrm{T}$ cells stimulated by virus-induced type I interferon. Nat Immunol 2003; 4: 1009-1015.

75 Lake RA, Robinson BW. Immunotherapy and chemotherapy - a practical partnership. Nat Rev Cancer 2005; 5: $397-405$.

76 Takahashi T, Carbone D, Nau MM, Hida T, Linnoila I, Ueda R et al. Wild-type but not mutant p53 suppresses the growth of human lung cancer cells bearing multiple genetic lesions. Cancer Res 1992; 52: 2340-2343.

77 Metcalf RA, Welsh JA, Bennett WP, Seddon MB, Lehman TA, Pelin K et al. p53 and Kirsten-ras mutations in human mesothelioma cell lines. Cancer Res 1992; 52: 2610-2615.

78 Giuliano M, Catalano A, Strizzi L, Vianale G, Capogrossi M, Procopio A. Adenovirus-mediated wild-type p53 overexpression reverts tumourigenicity of human mesothelioma cells. Int J Mol Med 2000; 5: 591-596.

79 Testa JR, Giordano A. SV40 and cell cycle perturbations in malignant mesothelioma. Semin Cancer Biol 2001; 11: $31-38$.

80 Wong L, Zhou J, Anderson D, Kratzke RA. Inactivation of p16INK4a expression in malignant mesothelioma by methylation. Lung Cancer 2002; 38: 131-136.

81 Frizelle SP, Rubins JB, Zhou JX, Curiel DT, Kratzke RA Gene therapy of established mesothelioma xenografts with recombinant p16INK $4 \mathrm{a}$ adenovirus. Cancer Gene Ther 2000; 7: 1421-1425.

82 Chin L, Pomerantz J, DePinho RA. The INK4a/ARF tumor suppressor: one gene - two products - two pathways. Trends Biochem Sci 1998; 23: 291-296.

83 Yang CT, You L, Lin YC, Lin CL, McCormick F, Jablons DM. A comparison analysis of anti-tumor efficacy of adenoviral gene replacement therapy (p14ARF and 
p16INK4A) in human mesothelioma cells. Anticancer Res 2003; 23: 33-38.

84 Yang CT, You L, Yeh CC, Chang JW, Zhang F, McCormick F et al. Adenovirus-mediated p14(ARF) gene transfer in human mesothelioma cells. J Natl Cancer Inst 2000; 92: 636-641.

85 Frizelle SP, Grim J, Zhou J, Gupta P, Curiel DT, Geradts J et al. Re-expression of p16INK4a in mesothelioma cells results in cell cycle arrest, cell death, tumor suppression and tumor regression. Oncogene 1998; 16: 3087-3095.

86 Pataer A, Smythe WR, Yu R, Fang B, McDonnell T, Roth JA et al. Adenovirus-mediated Bak gene transfer induces apoptosis in mesothelioma cell lines. $J$ Thorac Cardiovasc Surg 2001; 121: 61-67.

87 Mohiuddin I, Cao X, Fang B, Nishizaki M, Smythe WR. Significant augmentation of pro-apoptotic gene therapy by pharmacologic bcl-xl down-regulation in mesothelioma. Cancer Gene Ther 2001; 8: 547-554.

88 Benouchan M, Colombo BM. Anti-angiogenic strategies for cancer therapy (Review). Int J Oncol 2005; 27: 563-571.

89 Indraccolo S. Undermining tumor angiogenesis by gene therapy: an emerging field. Curr Gene Ther 2004; 4: 297-308.

90 Kuo CJ, Farnebo F, Yu EY, Christofferson R, Swearingen $\mathrm{RA}$, Carter $\mathrm{R}$ et al. Comparative evaluation of the antitumor activity of antiangiogenic proteins delivered by gene transfer. Proc Natl Acad Sci USA 2001; 98: 4605-4610.

91 Merritt RE, Yamada RE, Wasif N, Crystal RG, Korst RJ. Effect of inhibition of multiple steps of angiogenesis in syngeneic murine pleural mesothelioma. Ann Thorac Surg 2004; 78: 1042-1051; discussion 1042-1051.

92 Colombo MP, Trinchieri G. Interleukin-12 in anti-tumor immunity and immunotherapy. Cytokine Growth Factor Rev 2002; 13: 155-168.

93 Rosenberg SA, Yang JC, Restifo NP. Cancer immunotherapy: moving beyond current vaccines. Nat Med 2004; 10: 909-915.

94 Hassan R, Bera T, Pastan I. Mesothelin: a new target for immunotherapy. Clin Cancer Res 2004; 10: 3937-3942.

95 Thomas AM, Santarsiero LM, Lutz ER, Armstrong TD, Chen YC, Huang LQ et al. Mesothelin-specific CD8(+) T cell responses provide evidence of in vivo cross-priming by antigen-presenting cells in vaccinated pancreatic cancer patients. J Exp Med 2004; 200: 297-306.

96 Manfredi JJ, Dong J, Liu WJ, Resnick-Silverman L, Qiao $\mathrm{R}$, Chahinian $\mathrm{P}$ et al. Evidence against a role for SV40 in human mesothelioma. Cancer Res 2005; 65: 2602-2609.

97 Pass HI, Bocchetta M, Carbone M. Evidence of an important role for SV40 in mesothelioma. Thorac Surg Clin 2004; 14: 489-495.
98 Imperiale MJ, Pass HI, Sanda MG. Prospects for an SV40 vaccine. Semin Cancer Biol 2001; 11: 81-85.

99 Davidson JA, Musk AW, Wood BR, Morey S, Ilton M, Yu LL et al. Intralesional cytokine therapy in cancer: a pilot study of GM-CSF infusion in mesothelioma. J Immunother 1998; 21: 389-398.

100 Hecht JR, Bedford R, Abbruzzese JL, Lahoti S, Reid TR, Soetikno RM et al. A phase I/II trial of intratumoral endoscopic ultrasound injection of ONYX-015 with intravenous gemcitabine in unresectable pancreatic carcinoma. Clin Cancer Res 2003; 9: 555-561; 12: 737-748.

101 Uchino J, Takayama K, Harada A, Kawakami Y, Inoue H, Curiel DT et al. Infectivity enhanced, hTERT promoterbased conditionally replicative adenoviruses are useful for SCLC treatment. Cancer Gene Ther 2005; 12: 737-748.

102 Robinson BW, Creaney J, Lake R, Nowak A, Musk AW, de Klerk $\mathrm{N}$ et al. Mesothelin-family proteins and diagnosis of mesothelioma. Lancet 2003; 362: 1612-1616.

103 Urwin D, Lake RA. Structure of the Mesothelin/MPF gene and characterization of its promoter. Mol Cell Biol Res Commun 2000; 3: 26-32.

104 Harrington LE, Most RvR, Whitton JL, Ahmed R. Recombinant vaccinia virus-induced T-cell immunity: quantitation of the response to the virus vector and the foreign epitope. J Virol 2002; 76: 3329-3337.

$105 \mathrm{Yu}$ YA, Shabahang S, Timiryasova TM, Zhang Q, Beltz R, Gentschev I et al. Visualization of tumors and metastases in live animals with bacteria and vaccinia virus encoding light-emitting proteins. Nat Biotechnol 2004; 22: 313-320.

106 Xiang R, Mizutani N, Luo Y, Chiodoni C, Zhou H, Mizutani $\mathrm{M}$ et al. A DNA vaccine targeting survivin combines apoptosis with suppression of angiogenesis in lung tumor eradication. Cancer Res 2005; 65: 553-561.

107 Mizutani N, Luo Y, Mizutani M, Reisfeld RA, Xiang R. DNA vaccines suppress angiogenesis and protect against growth of breast cancer metastases. Breast Dis 2004; 20: 81-91.

108 Norman KL, Lee PW. Not all viruses are bad guys: the case for reovirus in cancer therapy. Drug Discov Today 2005; 10: $847-855$.

109 Myers R, Greiner S, Harvey M, Soeffker D, Frenzke M, Abraham $\mathrm{K}$ et al. Oncolytic activities of approved mumps and measles vaccines for therapy of ovarian cancer. Cancer Gene Ther 2005; 12: 593-599.

110 Tseng JC, Levin B, Hurtado A, Yee H, Perez de Castro I, Jimenez $\mathrm{M}$ et al. Systemic tumor targeting and killing by Sindbis viral vectors. Nat Biotechnol 2004; 22: 70-77.

111 Kucharczuk JC, Randazzo B, Chang MY, Amin KM, Elshami AA, Sterman DH et al. Use of a 'replicationrestricted' herpes virus to treat experimental human malignant mesothelioma. Cancer Res 1997; 57: 466-471. 